\title{
Influence of Attachment Styles on Academic Performance of Adolescents in High Cost Private Secondary Schools in Nairobi County, Kenya
}

\author{
Evelyn Majimbo, MA (Marriage and Family Therapy) \\ Marksign Media Promotion, Kenya
}

doi: 10.19044/esj.2017.v13n10p90 URL:http://dx.doi.org/10.19044/esj.2017.v13n10p90

\begin{abstract}
The purpose of the study was to determine the effect of adolescent attachment styles on academic performance in high-cost private secondary schools. The specific objectives were: to establish the attachment styles exhibited by the adolescents, to determine the relationship between attachment styles and academic performance of students in selected high cost secondary schools in Nairobi and to assess the role of parental bonding on adolescent attachment. Descriptive research design was used. The target population was students drawn from high cost private secondary schools in Dagoreti, Langata and Westlands constituencies in Nairobi County, Kenya. Data was collected by aid of a structured questionnaire with closed and openended questions. Data was analyzed using correlation technique and MannWhitney $U$ test. The results showed that there was a weak positive correlation between academic performance and secure attachment style and a negative correlation between academic performance and insecure attachment style. In overall, securely attached adolescents performed better than their insecure attached counterparts. Parents placed too much expectation on their adolescents which increased their anxiety and stress during exams. The implication of this is that parents unknowingly cause psychological harm by pushing their adolescents too much to excel in their education. Counseling practitioners attached to high cost private secondary schools should adopt a tripartite framework of guidance and counseling that involves the participation of parents through mutual understanding and child-centered engagement. Parents of these children should also be realistic even when they set their well-intended bar high for their adolescent children.
\end{abstract}

Keywords: Attachment Styles, Parental Bonding, Adolescent Attachment, Academic Performance 


\section{Introduction}

Attachment is an interactive process of emotional communication that influences psychological and cognitive growth (Heidi \&Solomon, 2006) and determine how a child relate later in life (Brown \&Wright, 2003). Attachment styles among adolescents are established early in life through interactions between children and their primary caregiver(s) (Rodrigue \& Reeves, 2015). The interactions potentially explain individual differences in how young brains process socio-emotional information.

According to Berman, Weems, Rodriguez and Zamora (2006), adolescents with secure attachment style demonstrate a host of individual socio-emotional benefits. Two of the most notable positive associations include self-concept and emotional regulation. Such adolescents tend to display higher levels of identity development. As older children, they have positive and open interactions (Behrens, Hesse \& Main, 2007). The parents of secure adolescents model warmth, sensitivity and positive emotions. Children living with warm and responsive parents learn to get along better with teachers and peers (Stright, Gallagher \& Kelley, 2008).

Csikszentmilahyi (2002) suggests that adolescents face various challenges as they try to discover themselves. They face increasing pressure from their parents who expect them to perform better for them to succeed. This is mostly experienced by children from affluent families whose parents push them to work hard in school. However, this may trigger conflict between parents and children which pushes them into antisocial behavior (Cook, Spinazzola, Ford, Lantree, Blaustein, Cloitre, \& Van der Kolk, 2005).

According to Luthar (2003), adolescents in high-cost private schools live a life of material luxury and fun iced with holiday trips and experience in top international schools. They do not shop at ordinary malls, and they ride in sleek vehicles. Their weekends are full and include anything from flying to their beach houses in Mombasa or simply a road trip to Sagana for white water rafting and bungee jumping. If there is not much happening, they ride their motorbikes into country clubs for drinks. The majority of them have never been to the city centre of Nairobi as their lives revolve around their suburb homes, high-cost schools and travels out of town. Despite the resources ostensibly available to them, nearly one out of ten of every adolescent exhibit high levels of behaviour disturbances and concurrently experience significant risk for poor grades in school.

Luthar and Becker (2002) established that excessive pressure from parents mostly causes psychological challenges among adolescents from affluent families. The scholars argued that most parents place high expectations on their children and pressurise them to perform well in school and to be successful in life. The affluent parents tend to have an overscheduled day while their children participate in numerous extracurricular 
activities which are expected to give them an added advantage when applying for competitive college spaces. In turn, the family misses out on bonding. This affects the attachment process.

Many studies have been undertaken on the factors influencing academic achievement in secondary schools in Kenya (Gitome, Katola, \&Nyabwari, 2013; Korir\&Kepkemboi, 2014; Koskei, 2014; Makworo, Wasanga \& Olaly, 2014; Nyagosia, Waweru \& Njuguna, 2013; Onderi, Kiplangat, \& Awino, 2014). All these studies focused on public secondary schools but few studies have been conducted in private schools.

The study by Koskei (2014) examined the influence of parental involvement on students' academic performance and found that parental involvement in education had no significant influence on academic performance of secondary students. Koskei speculated that unreasonably high demand and too much pressure for good performance made by some parents on their children may cause anxiety and fear of failure which may affect the child's academic performance negatively. However, there was no evidence from Koskei's research finding to support this claim and neither did he undertake the investigation from the perspective of adolescent attachment styles. Onderi et al., (2014) acknowledged that performance of students is a product of socio-economic, psychological and environmental factors but did not study the correlation between attachment styles and academic performance. An attempt was made by Makworo et al., (2014) to establish the psychological factors affecting girls' academic performance in secondary schools in Kenya where they found that $51.7 \%$ of the girls in their study portrayed a negative academic self-concept.

In a study by Kibaara and Kabura (2013) on factors influencing academic performance in Kibera which is a low income area located in Langata constituency in Nairobi Kenya, it was recommended that research should be carried out on factors affecting the academic performance of students in private schools. Orodho (2002) suggested that attachment styles may have an influence on the academic achievement of adolescents. However, little is known about how adolescent attachment styles affect academic performance in high cost private schools.

It is expected that high school students from affluent family backgrounds should perform better academically than those from public schools due to the abundance of wealth that enables them to study in schools with the best learning facilities and resources. However, statistics obtained from the Kenya National Examination Council suggest that students from high-cost private secondary schools are academically outperformed by students from their public school counterparts despite their affluent family backgrounds. Among the top 100 positions nationally, private schools only accounted for $28 \%, 27 \%$ and $29 \%$ of the best performing students in the 
years 2011, 2012 and 2013 Kenya Certificate of Secondary Education examinations, respectively.

Many studies which have been undertaken on the factors influencing academic achievement in secondary schools in Kenya focused on public secondary schools but few studies have been conducted in private schools. This study sought to investigate how attachment styles influence the academic performance of adolescents from Kenya's high-cost private schools. The current study focused on the influence of attachment styles on the academic performance of adolescents in high cost private secondary schools in Nairobi County where seventy-five percent of Kenya's affluent families live (Situma, 2014). The study sought to achieve the following objectives:

i) To establish the attachment styles exhibited by the adolescents in selected high cost private secondary schools in Nairobi, Kenya.

ii) To determine the relationship between attachment styles and academic performance of students in selected high cost secondary schools in Nairobi, Kenya.

iii) To assess the role of parental bonding on adolescent attachment in selected high cost private secondary schools in Nairobi, Kenya.

\section{Literature Review}

Attachment theory lays importance on early experiences of a child and how this affects them for the rest of their life. This is anchored on the findings of Bowlby (1977, p. 203) who concluded that the attachment system is experienced by all individuals from "the cradle to the grave". Without early diagnosis and treatment, adolescents who experience inappropriate attachment can have problems at home, in school, and in forming friendships. The improper attachment also interferes with their healthy development (intellectually, emotionally and socially) and these problems can continue into adulthood.

Based on numerous observations and studies, three attachment styles have been identified which persist in the quality of childhood/teenage engagements. These are: secure, avoidant and ambivalent. The latter two make up the combined category commonly referred to as "insecure." Through an experiment, Ainsworth (1979) realized three different types of attachment styles. Avoidant insecure attachment (A) is where a child will not show much concern or emotion whether the care giver is there or not. The avoidant child does not exhibit any distress at all. Ainsworth and Bell (1970) theorized that this unfulfilled behaviour was a way of coping with pain. Scroufe and Waters (1977) confirmed this later through examining the heart rate of the avoidant infant. The child showed increased heart rate despite the 
proximity to the mother. This implied the avoidant child was not sufficiently engaged.

The other attachment style is the secure attachment (B). In this category of attachment; the child explores the environment they are in with the knowledge that they have a stable base. When a stranger comes their way they may become uncomfortable for a while but quickly reconnects to their caregiver when they return. The third style is the anxious-ambivalent (C). Children in this attachment pattern show distress even when the caregiver is present. They are clingy and are not easy to comfort when they are in distress. They at times exhibit signs of resentment or helplessness (Ainsworth, Blehar, Waters, \& Wall, 1978). Later on, Main and Solomon (1990) added a fourth attachment style known as disorganized or disoriented attachment style (D). In this category, children seemed confused. They exhibited both features such as "substantial proximity seeking" and avoidant. At times they appeared dazed on the return of their caregiver.

The relevance of this theory is that parents play a very critical role in shaping the mindset and the behaviour of their children right from the infant stage. A well-established relationship between a parent and a child enhances the level of understanding and creates strong bonds and respect between the two. It is the presence and strength of that bond that determines attachment styles at adolescence and potentially influences the adolescent's academic performance.

Research has established that children from affluent families are more vulnerable to several mental health problems as a result of weak attachment, including anxiety disorders, depression, and chemical abuse than kids living in poverty (Luthar \& Latendresse, 2005). Adolescents from affluent families rarely spend time with their parents and therefore do not connect with their parents. Mugambi and Gitonga (2015) did a study in 5 private secondary schools in Westlands, Nairobi and established that major stressor among the adolescents was due to uncaring and/or abusive parents. Affluent parents are often too busy and are more inclined to give presents than their presence. Also, teenagers from wealthy families commonly feel high expectations for achievement in all areas. This study discusses the influence of attachment styles in the life of an adolescent, especially in their academic performance. It brings out the attachment in adolescence, the relationship between attachment and education and how connectedness or lack thereof, and prolonged isolation affects the development of an adolescent.

In another study conducted in public secondary, schools in Nairobi, Khasakhala, Ndetei, Mutiso, Ambwayo, and Mathai (2012) concluded that maternal rejecting parental behaviour, paternal under protective response and no emotional attachment parental behaviour were associated with 
maladaptive behaviours. The study was supported by previous studies which showed that children raised in such environments were vulnerable to developmental health challenges (Leinonen, Solantaus \& Punamaki, 2003).

In the recent past, there have been discussions around the issue of parents and adolescents relationship with some studies showing that parents are not very important in the lives of adolescence. However, there is data to show that parents do make a significant difference when involved in the lives of adolescents (Moretti \& Holland, 2003). Evidence-based studies clearly show that there is a relation between secure attachment and school outcomes. The results include execution of tasks and resilience (Kerns, 2008). There is more chance of children in elementary classes to perform well in school when securely attached. Mother's responsiveness and warmth was shown to have an influence on the math and reading performance in the third grade (National Institute of Child Health and Human Development Early Child Care Research Network, 2008). An Israeli study depicted the perception of secure children by their teachers as socially and intellectually competent. Their peers too had the same idea (Granot \& Mayseless, 2001). New research points to the fact that enhanced performance happens in different areas of an individual's life with socio-proximity (Kraus, Huang, \& Keltner, 2010). Research has inextricably linked attachment in early life to school readiness and learning success (Commodari, 2013).

In a study by Moullin, Waldfogel and Washbrook (2014), there were indications that the emotional ties a child secured with her caregiver influences their education and predict their ability to learn, think and speak. The authors anchored their report on attachment theory which is a key theory in child development. The study was done across a range of countries and analyzed more than 100 studies performed in homes, through interviews and observations. The findings indicated that children who are insecurely attached are likely to be aggressive among other problem behaviours and drop out of school and more likely to fall out of employment in future.

Karega (2012) used the attachment theory to explain the importance of parent's involvement through love, parental support, and acceptance of the adolescent as a control against problem behaviours. The findings suggested that parental bonding was negatively correlated to problem behavior among adolescent students. Mugambi and Gitonga (2015) concurred with Powers and Welsh (1999) that most clearly established challenge adolescents face is because of an uncaring parent. In their study on adolescents from private secondary schools from Westlands, they realized the following findings as major risk factors; being misunderstood by parents, traumatic experience, parents unhealthy relationships, sidelined by friends, studies related problems, pessimism, bad childhood memories and addictions. This finding is supported by Khasakhala et al., (2012) who established that 25\% of 
adolescents in secondary schools in Nairobi suffer major depressive disorder which is associated with maladaptive parenting.

Studies have indicated that responsive and engaged primary caregiving is related to cognitive development (Kerns, 2008).) Children's success in education is closely linked to attachment with their parents. Researchers ascertain that security of attachment determines academic achievement. Studies show that insecurely attached pre-school children have a short attention span with poor cognitive skills unlike their secure counterparts (Moss \& St. Laurent, 2001). Children whose parents model warmth and responsiveness are socially competent and easily get along with peers and teachers (Stright et al., 2008). The current study sought to establish whether the affluent adolescents in Nairobi were influenced by their attachment styles in regard to their academics.

\section{Research Methodology}

This study used a descriptive research design. According to Mugambi and Gitonga (2015), the total population of students in private secondary school in the study area was 6,761 students. For this study, three purposively selected constituencies namely Westlands, Dagorreti and Langata which are all located to the west of Nairobi City were considered. The researcher purposively focused on Westlands, Dagorreti and Langata because this is where 75 percent of the high cost private secondary schools are located. These constituencies play host to the majority of the high-cost private schools in Nairobi and therefore the study appropriately reflected the position of the target population. The western part of Nairobi was a preserve for the Europeans and the wealthy Asians during the colonial era and is where most of the high cost private secondary schools are located. They include Karen, Langata, Lavington, Westlands, Muthaiga, Muthangari, Runda, Riverside, Springvalley, Loresho, Kilimani, Kileleswa, Hurlingham, Kitusuru, Lower Kabete, Highridge, Nyari and Kyuna. These locations fall into three constituencies. These areas host the wealthy Kenyans of all ethnic groups and are in Nairobi's posh residential estates. They are home to Nairobi's high-cost schools, malls, restaurants and various activity sites like golf and country clubs, animal parks and orphanages. In the high cost category, the three constituencies have 4 boys' only schools, 5 girls' only schools and 20 mixed schools. Three schools, one from each constituency were purposively chosen for a balanced representation of the constituencies. In these three schools, the total population of adolescents was 1,610.

The sample size for this study was a total of 161 respondents, equivalent to $10 \%$ of the target population as recommended by Mugenda and Mugenda (2003). The sampling frame was the enrollment record obtained from the respective school's admissions office. Stratified random sampling 
procedure was used. Data was collected using a questionnaire. A modified version of Behavioral Systems Questionnaire (BSQ) used by Cortesi (2014) to study the impact of adolescent attachment on academic success was used. The questionnaire consisted of both open-ended and closed-ended questions. The open-ended sections sought to gather the thoughts and beliefs of the respondents in how they related with their parents. The questionnaire was physically administered by the researcher who visited the selected schools and conducted the interview during class recess.

Descriptive statistics such as percentages, frequencies and median scores were established. Inferences were drawn using Mann-Whitney U test and correlation technique. The BSQ scores were calculated by obtaining the mean of each item as suggested by Cortesi (2014). According to Carver and Nash (2008), this test is performed on two independent samples whose data is ordinal. In this case, the two independent samples were secure attachment and insecure attachment. The hypothesis tested was that adolescent attachment styles affected their academic performance. The procedure for undertaking this involved combining all the scores for both groups and ranking them. Qualitative data was analyzed using thematic techniques. The Statistical Package for the Social Sciences (SPSS) was used for data analysis.

\section{Results and Discussions}

The study established that most of the respondents performed relatively poorly academically as more than half (52.6\%) scored grade C plain and below in their last academic term as shown in Table 1. It is instructive to note that the minimum grade required for university entry in Kenya is $\mathrm{C}+$. Most of the respondents indicated that it was almost always true that they felt stressed about exams but were never showing it. This resonates with avoidant insecure attachment as explained by Ainsworth and Bell (1970) who observed that a child in this category of attachment style will not exhibit any distress at all as a way of coping with pain.

Table 1. Respondent's mean grade for the last academic term

\begin{tabular}{ccc}
\hline Mean grade & Frequency & Percent \\
\hline C (plain and below) & 83 & 52.6 \\
C+ & 18 & 11.2 \\
B & 23 & 14.5 \\
B+ & 18 & 11.2 \\
A- & 9 & 5.9 \\
A & 7 & 4.6 \\
\hline Total & 157 & 100.0 \\
\hline
\end{tabular}

As indicated in Table 2, Spearman's rank correlation coefficients of attachment style on academic performance showed that there was a statistically significant inverse relationship between academic performance 
and avoidant attachment style $(r=-.203, p<.05)$, ambivalent attachment style $(r=-.239, p<.05)$ and disorganized attachment style $(r=-.199, p<.05)$. However, the correlation between secure attachment style, although positive, was not statistically significant $(r=.117, p>.05)$. The results imply that as insecure attachment increased, academic performance declined. This agrees with the perspective of Muola (2010) that students in the category of insecure attachment end up with conditions such as anxiety and fear of failure causing them to perform poorly academically as a result of pressure from their parents.

Table 2. Correlation between attachment styles and academic performance

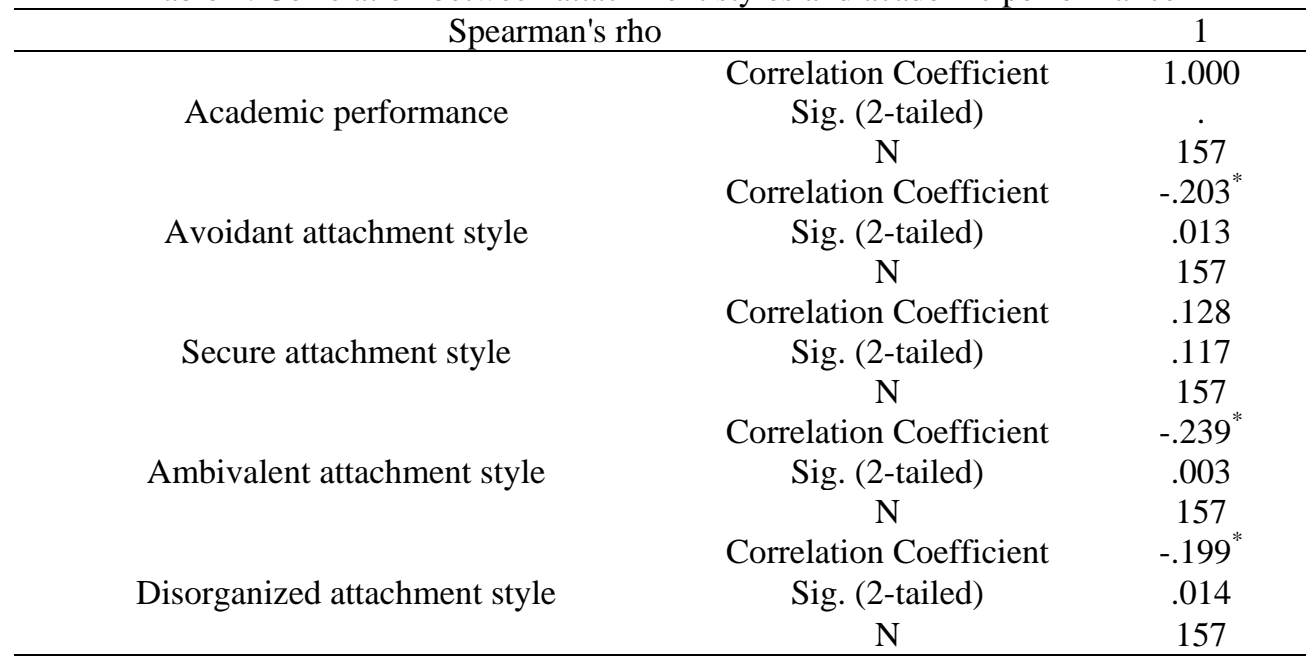

Mann-Whitney $\mathrm{U}$ test (Tables 3 and 4) showed that respondents presenting secure attachment style scored higher academic performance than respondents exhibiting insecure attachment style. This suggests that insecurely attached respondents performed relatedly poorly compared to secure attached respondents $(z=-1.895, p=.05)$. Insecure attachment group had an average rank of 70.59 while secure attachment group had an average rank of 83.15 .

Table 3. Ranks

\begin{tabular}{ccccc}
\hline & Attachment style & N & Mean Rank & Sum of Ranks \\
\hline \multirow{3}{*}{ Academic performance } & Insecure attachment & 90 & 70.59 & 6071.00 \\
& Secure attachment & 67 & 83.15 & 5405.00 \\
\cline { 2 - 5 } & Total & 157 & & \\
\hline
\end{tabular}

Table 4. Test Statistics ${ }^{\mathrm{a}}$

\begin{tabular}{cc}
\hline & Academic performance \\
\hline Mann-Whitney U & 2330.000 \\
Wilcoxon W & 6071.000 \\
Z & -1.895 \\
Asymp. Sig. (2-tailed) & .05 \\
\hline
\end{tabular}

a. Grouping Variable: Attachment Style 
A thematic analysis of the qualitative data extracted from verbatim comments of respondents concerning parental bonding revealed that the bond was stronger between the mothers and their adolescent children on all dimensions of parental bonding than between the fathers and their adolescent children. The dimensions analyzed included parent's role in anxiety towards exams, perceptions about care, attention from parents and quality time with parents. This could be explained by an influence from the Kenyan cultural orientation which dictates that the mother is the one held responsible in the bringing up of the children.

As shown in Figure 1, it was found that $51 \%$ of the respondents' parents played a negative role on the anxiety respondents had towards the exam. These respondents commented that their parents expected too much from them, which increased their anxiety. This agrees with the claim by Khasakhala et al., (2012) that adolescents in Kenya undergo psychosocial challenges due to pressure from parents and too many expectations from the society. It also agrees with the finding by Muola (2010) which showed that having wealthy parents with high expectations and aspirations resulted in a stressful life for children. This finding corroborates the perspective of Luthar and Becker (2002) that most parents place high expectations on their children and pressurize them to perform well in school and to be successful in life, usually, at the expense of the adolescent's emotional health. Nonetheless, $49 \%$ of the respondents' parents played a positive role. Respondents in this category commented that their parents were encouraging.

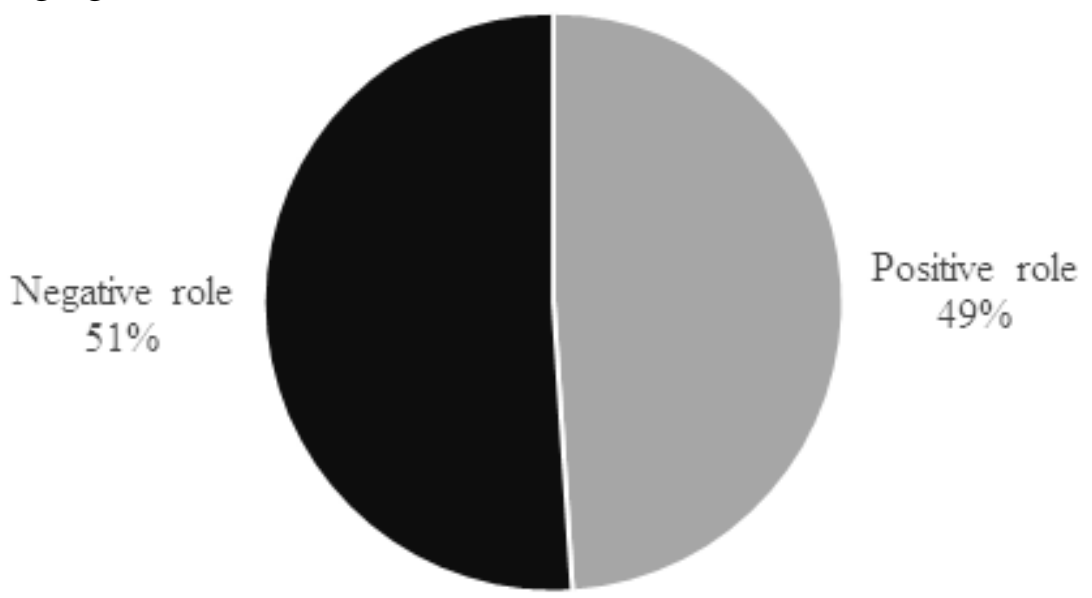

Figure 1. Role of parents on anxiety towards exams

In sum, it can be inferred from the findings that in times of distress the brain activities might have been guided by the level of how securely attached a student was. The level of secureness seemed to also dictate one's emotional regulation (the feelings of anxiety for example), which if not 
appropriately regulated, affects the activities in the brain as revealed by Coan, Schaefer and Davidson (2006) in the shock threat study with different scenarios of security. This implies that during moments of stress or duress the brain functions prioritizes survival over critical thinking hence making it a challenge for the respondents to access their reasoning and logic making centres in the brain which they need to excel in their academics.

\section{Conclusion}

In varying degrees, all the attachment styles were exhibited by the adolescents. The most manifest aspect of adolescent attachment among high cost private secondary schools under study were insecure avoidant attachment style. This is because majority of the respondents did not show distress on the prospect of sitting exams. However this does not mean that they did not feel anxious about exams but rather, it was a way of managing the anxiety. This is in line with Attachment Theory as put forward by Ainsworth and Bell (1970). Thus, there were potentially underlying causes of the attachment styles exhibited by the adolescents under study that practitioners should resolve.

Adolescent attachment style did influence academic performance in the sense that high performance was exhibited among secure attachment group compared to their insecure counterparts. This is consistent with Moullin et al.'s (2014) study which linked attachment style of school pupils with their performance in education. Specifically, academic performance decreased with rise in insecure attachment elements on all the three archetypes, namely: disorganized, avoidant and ambivalent attachment. However, this relationship was weak. The implication of this is that adolescent attachment style may not be the only factor explaining poor academic performance of students in high cost secondary schools.

Adolescents from affluent families used avoidant insecure attachment style as a strategy to manage stressful situations in their academic life. Their source of stress was not the exam per se but the high expectations of their parents whom they did not want to disappoint. This concurs with a previous study in Kenya by Khasakhala et al., (2012) who associated high pressure from parents with adolescent's stress. Suprisingly, these high expectations prevailed irrespective of the strength of bonding that subsisted between the parents and their adolescent child, meaning that although parental bonding was potentially instrumental in adolescent attachment formation, it did not play a significant role moderating the child's anxiety towards exams. The result is an unnecessary anxiety and stress that negatively impacts on their academic performance. Parents of these children should therefore be realistic even when they set their well-intended bar high for their adolescent children. It is important that parents find a way of involving their children in setting 
their expectations in order to relate with their adolescent children in a more productive manner. Counseling practitioners attached to high cost private secondary schools should adopt a tripartite framework of guidance and counseling that involves the participation of parents and the adolescent through mutual understanding and child-centered engagement.

\section{References:}

1. Ainsworth, M. D. S. \& Bell, S. M. (1970). Attachment, exploration, and separation: Illustrated by the behaviour of one-year-olds in a strange situation. Child Development, 41, 49-67.

2. Ainsworth, M. D. S. (1979). Infant -mother attachment. The American Psychologist, 34(10), 93-937.

3. Ainsworth, M.D.S., Blehar, M.C., Waters, E., \& Wall, S. (1978). Patterns of attachment: A psychological study of the strange situation. Hillsdale, NJ: Lawrence Ernbaum.

4. Behrens, K. Y., Hesse, E., \& Main, M. (2007). Mothers' attachment status as determined by the adult attachment interview predicts their 6-year olds reunion responses: A study conducted in Japan. Developmental Psychology, 43(6), 1553-1567.

5. Berman, S.L.,Weems, C. F., Rodriguez, E. T., \& Zamora, I. J. (2006). The relation between identity status and romantic attachment style in middle and late adolescence. Journal of Adolescence, 29, 737-748

6. Bowlby, J. (1977). The making and breaking of affectional bonds: aetiology and psychopathology in the light of attachment theory. British Journal of psychiatry, 130, 201-210.

7. Brown, L. S., \& Wright, J. (2003).The relationship between attachment strategies and psychopathology in adolescence. Psychology \& Psychotherapy: Theory, Research \& Practice. 76 (4) 351-367

8. Carver, R. H. \& Nash, J. G. (2008).Doing data analysis with SPSS: Version 16.0.New York, NY: Cengage Learning.

9. Coan, J.A., Schaefer, H. S., \& Davidson, R. J. (2006).Lending a hand: Social regulation of the neutral response to threat. Psychological Science, 17(12), 1032-1039.

10. Commodari, E., (2013), Preschool teacher attachment, school readiness and risk of learning difficulties. Early childhood Research Quarterly, 28(1), 123-133

11. Cook, A., Spinazzola, J., Ford. J., Lantree, C., Blaustein M., Cloitre, M., Van der Kolk, B., (2005). Complex trauma in children and adolescents. Psychiatric Annals. 35 (5) 390-398. 
12. Cortesi, C. (2014). Understanding the impact of adolescent attachment on academic success. Dissertations. Paper 893. Retrieved on $5^{\text {th }}$ May 2016 from http://ecommons.luc.edu/luc_diss/893

13. Csikszntmihalyi, M. (2002). Flow: the classic work on how to achieve happiness. London, UK: Rider.

14. Gitome, J. W., Katola, M. T. \&Nyabwari, B. G. (2013).Correlation between students' discipline and performance in the Kenya Certificate of Secondary Education. International Journal of Education and Research, 1(8), 1-10.

15. Granot, D., \&Mayseless, O. (2001).Attachment security and adjustment to school in middle childhood. International Journal of Behavioural Development. 25, 530-541.

16. Heidi, K.M., \& Solomon, E. P. (2006). Biology, childhood trauma and murder: Rethinking justice. International journal of law and psychiatry.29, 220-2233

17. Karega, M. (2012).Relationship between perceived parental nurturance and problem behaviours among secondary school students in selected counties in Kenya. Retrieved on $2^{\text {nd }}$ May 2016 from http://handle.library.ku.ac.ke/bitstream.

18. Kerns, K. (2008). Attachment in middle childhood. In J. Cassidy, \& P.R. Shaver (Eds.), Handbook of attachment: Theory, research and clinical applications. New York, NY: The Guilford Press.

19. Khasakhala L. I., Ndetei, D.M., Mutiso,V., Ambwayo, A.W., Mathai,M. (2012). The prevalence of depressive symptoms among adolescents in Nairobi public secondary schools: association with perceived maladaptive parental behaviour. Africa Journal psychiatry, 15(1), 106-113.

20. Kibaara, T., \&Kabura, W.G., (2013) Factors influencing academic performance in urban informal settlements in Kenya; A case study of public primary schools of Kibera slums, Nairobi county. Retrieved on $3^{\text {rd }}$ May 2016 from http://ir.kabarak.ac.ke

21. Korir, D. K. \& Kipkemboi, F. (2014). The impact of school environment and peer influences on students' academic performance in Vihiga County, Kenya. International Journal of Humanities and Social Sciences, 4(1), 240-251.

22. Koskei, B. K. (2014). Influence of parental involvement on students' academic performance of public mixed day secondary schools in Kuresoi sub-county, Nakuru County, Kenya. International Journal of Education and Research, 2(12), 505-516.

23. Kraus, M. W., Huang, C., \&Keltner, D. (2010) Tactile communication, cooperation, and performance: An ethological study of the NBA. Emotion, 10(5), 745-749. 
24. Leinonen J.A., Solantaus T.S., \&Punamaki R. L., (2003).Parental mental health and children's adjustment; the quality of mental interaction and parenting as mediating factors. Journal of child psychology and psychiatry, 44(2), $227-241$.

25. Luthar, S. S. \& Latendresse, S. J. (2005). Children of the affluent: Challenges to well-being. Current Directions in Psychological Science, 14(1), 49-53.

26. Luther, S. S. \& Becker, B. E. (2002). Privileged but pressured? A study of affluent youth. Child Development, 73(5), 1593-1610.

27. Luther, S. S. (2003). The culture of affluence: psychological cost of material wealth. Child Development, 74(6), 1581-1593.

28. Main, M., \& Solomon, J. (1990). Procedures for identifying infants as disorganized/disoriented during the Ainsworth Strange Situation. In M.T. Greenberg, D. Cicchetti \& E.M. Cummings (Eds.), Attachment in the Preschool Years (pp.121-160). Chicago, University of Chicago Press.

29. Makworo, B. K., Wasanga, C. H. \&Olaly, W. (2014). Influence of parental involvement on students' academic performance of public mixed day secondary schools in Kuresoi sub-county, Nakuru County, Kenya. International Journal of Psychology and Counseling, 6(9), 119-132.

30. Moretti, M. M. \&Holland, R..(2003). Navigating the journey of adolescence: Parental attachment and the self from a systemic perspective. In: Johnson S. Whiffen V, editors. Clinical Applications of Attachment Theory. New York, NY: Guilford.

31. Moss, E., \& St-Laurent, D., (2001) Attachment at school age and academic performance. Developmental Psychology, 37(6), 863-874.

32. Moullin, S., Waldfogel J. \&Washbrook E. (2014).Baby bonds: Parenting, attachment and a secure base for children. London, UK: The Sutton Trust.

33. Mugambi, P. \&Gitonga, C. (2015).Adolescent awareness of the psychosocial risk factors for depression in selected secondary schools in Nairobi-Kenya. Journal of Education and social Research, 5(3)191-200.

34. Mugenda, O. M. \&Mugenda, A. G. (2003).Research methods: Quantitative and qualitative Approaches. Nairobi, KE: African Centre for Technological Studies.

35. Muola, J. M. (2010). A study of the relationship between academic achievement motivation and home environment among standard eight pupils. Educational Research and Reviews, 5(5), 213-217.

36. National Institute of Child Health and Human Development (NICHD) Early Child Care Research Network, (2008) Mothers and 
fathers support for child autonomy and early school achievement. Developmental Psychology, 44(4), 895-907.

37. Nyagosia, P. O., Waweru, S. N. \&Njuguna, F. W. (2013).Factors influencing academic achievement in public secondary schools in central Kenya: an effective Schools' perspective. Educational Research International, 2(2), 174-181.

38. Onderi, H., Kiplangat, R. K. \&Awino, J. (2014).Factors contributing to poor academic performance in Kenya Certificate of Secondary Education in public secondary schools in Kericho Sub-county , Kericho County, Kenya. Kenya Journal of Educational Planning, Economics \& Management, 7(2), 1-14.

39. Orodho, J. (2002). Essentials of educational and social sciences research methods. Nairobi, KE: Masola Publishers.

40. Powers, S. \& Welsh, D., P. (1999). Mother- daughter interactions and adolescent girl' depression. In: Conflict and Cohesion in Families. Mahwah, NJ: Lawrence Erlbaun Publishers.

41. Rodrigue, E. \& Reeves, R.V. (2015) Getting attached: Parents attachment and child development centre on children and families. Retrieved on $5^{\text {th }} \quad$ May 2016 from http://www.brookings.edu/blogs/social-mobility-memos/posts/

42. Scroufe, L. A. \& Waters, E. (1977).Attachment as an organizational construct. Child Development, 48(1), 1184-1199.

43. Situma, E. (2014). Nairobi home to 75 percent of the affluent in Kenya corporate news. Retrieved on $5^{\text {th }}$ April 2016 from http://www.mwakilishi.com/content/articles/2014/02/20/nairobihome-to-75-percent-of-the-affluent-in-kenya.html

44. Stright, A. D., Gallagher, K.C., \& Kelley, K. (2008). Infant temperament moderates relationships between maternal parenting in early childhood and children adjustment in first grade. Child Development 79 (1).186-200. 